\title{
A COMPARATIVE STUDY OF DEXMEDETOMIDINE AND CLONIDINE AS PREMEDICANT ON INTRAOCULAR PRESSURE AND HAEMODYNAMIC CHANGES IN NON-OPHTHALMIC SURGERIES
}

\author{
Preeti Yadav1, Anita Pareek2, Aditi Sharma ${ }^{3}$ \\ ${ }^{1}$ Senior Resident, Department of Anaesthesia, SMS Medical College, Jaipur, Rajasthan. \\ 2 Professor, Department of Anaesthesia, S. P. Medical College, AGH, Bikaner, Rajasthan. \\ 3Intern Trainee, Lady Hardinge Medical College, New Delhi.
}

\section{ABSTRACT}

\section{BACKGROUND}

Laryngoscopy and tracheal intubation are associated with hypertension, tachycardia, increased circulating catecholamines and increase in intraocular pressure. Aim of this study is to compare the effect of IV Dexmedetomidine and IV Clonidine premedication on the intraocular pressure changes, haemodynamic responses after succinylcholine injection and intubation.

\section{METHODS}

Sixty cases both male and female patients ranging between the age group 18 to 60 years belonging to ASA 1 or ASA 2 grades, undergoing elective non-ophthalmic surgeries under general anaesthesia were studied. All patients were randomized into 3 groups of 20 patients each. Each group consists of 20 patients. Dexmedetomidine Group (Group 1) patients received intravenous Dexmedetomidine $1 \mathrm{micro} / \mathrm{kg}$ in $100 \mathrm{~mL}$ normal saline, Clonidine Group (Group 2) patients received intravenous Clonidine 1 micro/kg in $100 \mathrm{~mL}$ normal saline, Control Group (Group 3) patients received intravenous $100 \mathrm{~mL}$ saline infused over 10 minutes. Mean Arterial Pressure (MAP), Heart Rate (HR) and IOP were recorded at before premedication 5 min. after premedication, $30 \mathrm{~s}$ after succinylcholine, 1 min. after intubation, 5 mins. after intubation.

\section{RESULT}

Fall in Pulse rate, Systolic blood pressure. Diastolic blood pressure, Mean arterial pressure and intraocular pressure were observed following administration of dexmedetomidine and clonidine groups after suxamethonium injection and endotracheal intubation. Pulse rate, blood pressure (Systolic, Diastolic and Mean) and IOP differences were statistically significant ( $p$ value between 0.000 and 0.5 ) in dexmedetomidine and clonidine group compared to control groups 1 min. and 5 minutes after intubation, but it was statistically not significant between dexmedetomidine and clonidine group.

\section{CONCLUSION}

Dexmedetomidine ( 1 micro/kg) given 10 minutes before induction is much more effective in controlling both the tachycardia, hypertension and IOP following laryngoscopy and intubation as compared to inj. Clonidine (1 micro/kg) given 10 minutes before indication. So Dexmedetomidine is a better drug than Clonidine to attenuate the haemodynamic changes and IOP due to laryngoscopy and intubation.

\section{KEYWORDS}

Anaesthesia, Intraocular Pressure, Dexmedetomidine, Clonidine.

HOW TO CITE THIS ARTICLE: Yadav P, Pareek A, Sharma A. A comparative study of dexmedetomidine and clonidine as premedicant on intraocular pressure and haemodynamic changes in non-ophthalmic surgeries. J. Evolution Med. Dent. Sci. 2016;5(33): 1814-1818, DOI: $10.14260 /$ jemds/2016/427

\section{INTRODUCTION}

Laryngoscopy and Endotracheal intubation are employed for safe conduct of general anaesthesia. Laryngoscopy and tracheal intubation are associated with hypertension, tachycardia and increased circulating catecholamines. They are also associated with increase in intraocular pressure. ${ }^{1}$ Succinylcholine is used to facilitate rapid tracheal intubation, but is associated with and increase in the IOP. Intranasal nitroglycerine attenuated cardiovascular responses to laryngoscopy and intubation. ${ }^{2}$ Intravenous lignocaine could mitigate or prevent the ocular reactions and especially the acute increase in intraocular pressure associated with laryngoscopy and tracheal intubation. ${ }^{3}$

Financial or Other, Competing Interest: None.

Submission 08-03-2016, Peer Review 04-04-2016,

Acceptance 09-04-2016, Published 23-04-2016.

Corresponding Author:

Dr. Anita Pareek,

4/E/188, Behind Youth Fashion,

JNV Colony, Bikaner,

Rajasthan.

E-mail: dranitapareek23@gmail.com

DOI: $10.14260 /$ jemds/2016/427
Dexmedetomidine and Clonidine are two drugs which are $\alpha-2$ adrenergic agonists, which bestow the property of inhibiting dangerous rise in intraocular pressure during laryngoscopy and intubation following administration of suxamethonium. Clonidine, which was initially introduced as antihypertensive, is the most commonly used Alpha- 2 agonist by anaesthesiologists for its sympatholytic, sedative, anaesthetic sparing effects and haemodynamic stabilizing properties. 4

Clonidine is an imidazoline derivative, selective central $\alpha 2$ agonist with analgesic, antianxiety sedative, sympatholytic and haemodynamic stabilizing properties. Clonidine decreases IOP regardless if administered systemically or topically. Oral clonidine premedication resulted in adequate sedation, effective blunting of intraocular pressure and haemodynamic responses to laryngoscopy and endotracheal intubation following injection of suxamethonium. ${ }^{5}$

Dexmedetomidine is a highly selective alpha-2 adrenergic agonist that has sedative and analgesic effects. Alpha-2 agonists provide potentially beneficial effects in ophthalmic surgery because of their IOP lowering properties. 
Dexmedetomidine exert anaesthetic-sparing effects, increased haemodynamic stability and reduced unwarranted responses to endotracheal intubation. ${ }^{6}$ Some of well documented beneficial effects of dexmedetomidine are anxiolysis, sedation, analgesia and sympatholysis with minimal respiratory depression. It has been observed that the rise of IOP with suxamethonium and intubation can be blunted with dexmedetomidine premedication. ${ }^{7}$

In the year 2014, Shalini et $\mathrm{al}^{8}$ concluded that dexmedetomidine premedication obtund the intraocular pressure rise after suxamethonium and endotracheal intubation. Aim of this study is to compare the effect of IV dexmedetomidine and IV clonidine premedication on the intraocular pressure changes haemodynamic responses after succinylcholine injection and intubation.

\section{METHODS}

This study was conducted in the Department of Anaesthesiology, Sardar Patel Medical College and Associated Group of Hospitals, Bikaner, after taking consent from Institutional Research Board. Sixty cases both male and female patients ranging between the age group 18 to 60 years belonging to ASA 1 or ASA 2 grades undergoing elective nonophthalmic surgeries under general anaesthesia were studied.

Patients aged $<18$ years and $>60$ years, obese $>30$ BMI with any ophthalmic diseases, on sedatives, hypnotic and antidepressants or allergy to anaesthetic drugs and patients with predicted difficult airway were excluded from this study. All patients were randomized into 3 groups of 20 patients each and an effort was made that the group do not significantly differ with respect to age, weight and height.

- $\quad$ Each group consisted of 20 patients.

- Group I- Dexmedetomidine Group.

- Group II- Clonidine Group
- Group III- Control Group.

On arrival in the operation theatre, Systolic Blood Pressure (SBP), Diastolic Blood Pressure (DBP), Mean Arterial Pressure (MAP), Pulse rate and Saturation of oxygen $\left(\mathrm{SpO}_{2}\right)$ were recorded on Space Lab Work Station monitor. Intraocular Pressure (IOP) was measured using Schiotz indentation tonometer after prior instillation of local anaesthetic topical lignocaine $4 \%$ eye drops.

Group I (Dexmedetomidine Group) patients received intravenous Dexmedetomidine $1 \mu \mathrm{g} / \mathrm{kg}$ in $100 \mathrm{~mL}$ normal saline infused over 10 minutes.

Group II (Clonidine Group) patients received intravenous Clonidine $1 \mu \mathrm{g} / \mathrm{kg}$ in $100 \mathrm{~mL}$ normal saline infused over 10 minutes.

Group III (Control Group) patients received intravenous $100 \mathrm{~mL}$ normal saline infused over 10 minutes.

After pre-oxygenation for $3 \mathrm{~min} .$, patients were induced with a sleep dose of $2.5 \%$ solution thiopentone sodium. Inj. Succinylcholine $1.5 \mathrm{mg} / \mathrm{kg}$ was given after disappearance of eye lashes reflex to achieve muscular relaxation for intubation. After cessation of fasciculation, the trachea was intubated under direct vision laryngoscopy. Anaesthesia was maintained with IPPV $\mathrm{N}_{2} \mathrm{O}$ (66\%), $\mathrm{O}_{2}$ (33\%), halothane and inj. vecuronium bromide.

Mean Arterial Pressure (MAP), Heart Rate (HR), and IOP were recorded at the following time points

- T1: Before Premedication (Baseline).

- T2: 5 min. after Premedication.

- T3: $30 \mathrm{~s}$ after Thiopental.

- T4:30 s after Succinylcholine.

- T5: 1 min. after Intubation.

- T6: 5 min. after Intubation.

OBSERVATIONS/Statistical Analysis of Pulse Rate (min) in all Three Groups

\begin{tabular}{|c|c|c|c|c|c|c|}
\hline \multirow{2}{*}{ Time } & \multicolumn{2}{|c|}{ Dexmedetomidine } & \multicolumn{2}{|c|}{ Clonidine } & \multicolumn{2}{|c|}{ Control } \\
\hline & Mean & SD & Mean & SD & Mean & SD \\
\hline T1(Before premedication) & 87.30 & 8.34 & 91.40 & 9.22 & 79.65 & 7.24 \\
\hline T2 (5 min after premedication) & 74.30 & 7.31 & 81.80 & 7.81 & 79.25 & 8.15 \\
\hline T3 (30 sec after thiopental) & 74.10 & 7.88 & 84.60 & 8.90 & 85.05 & 7.03 \\
\hline T4 (30 sec after succinylcholine) & 78.65 & 7.88 & 88.55 & 9.24 & 92.50 & 6.44 \\
\hline T5 (1 min after intubation) & 84.10 & 7.05 & 94.05 & 9.90 & 112.85 & 9.63 \\
\hline T6 (5 min after intubation) & 78.90 & 7.69 & 85.75 & 7.96 & 94.95 & 7.30 \\
\hline & & & & & $\mathrm{T}$ & $\mathrm{P}$ \\
\hline & & Group I & oup II & & 1.475 & 0.149 \\
\hline $\mathrm{T} 1$ & & Group I & oup III & & 3.098 & 0.004 \\
\hline & & Group II & oup III & & 4.481 & $<0.001$ \\
\hline & & Group I & oup II & & 3.135 & 0.003 \\
\hline $\mathrm{T} 2$ & & Group I & oup III & & 2.022 & 0.050 \\
\hline & & Group II & oup III & & 1.010 & 0.319 \\
\hline & & Group I & oup II & & 3.950 & $<0.001$ \\
\hline T3 & & Group I & oup III & & 4.637 & $<0.001$ \\
\hline & & Group II & oup III & & 0.177 & 0.860 \\
\hline & & Group I & oup II & & 3.646 & 0.001 \\
\hline $\mathrm{T} 4$ & & Group I & oup III & & 6.087 & $<0.001$ \\
\hline & & Group II & oup III & & 1.569 & 0.125 \\
\hline & & Group I & oup II & & 3.662 & 0.001 \\
\hline $\mathrm{T} 5$ & & Group I & oup III & & 10.773 & $<0.001$ \\
\hline & & Group II & oup III & & 6.088 & $<0.001$ \\
\hline & & Group I & oup II & & 2.768 & 0.009 \\
\hline T6 & & Group I & oup III & & 6.768 & $<0.001$ \\
\hline & & Group II & oup III & & 3.809 & $<0.001$ \\
\hline
\end{tabular}

$P$ value $<0.05$ - Significant 
Statistical Analysis of Mean Arterial Pressure (mmHg) in all Three Groups

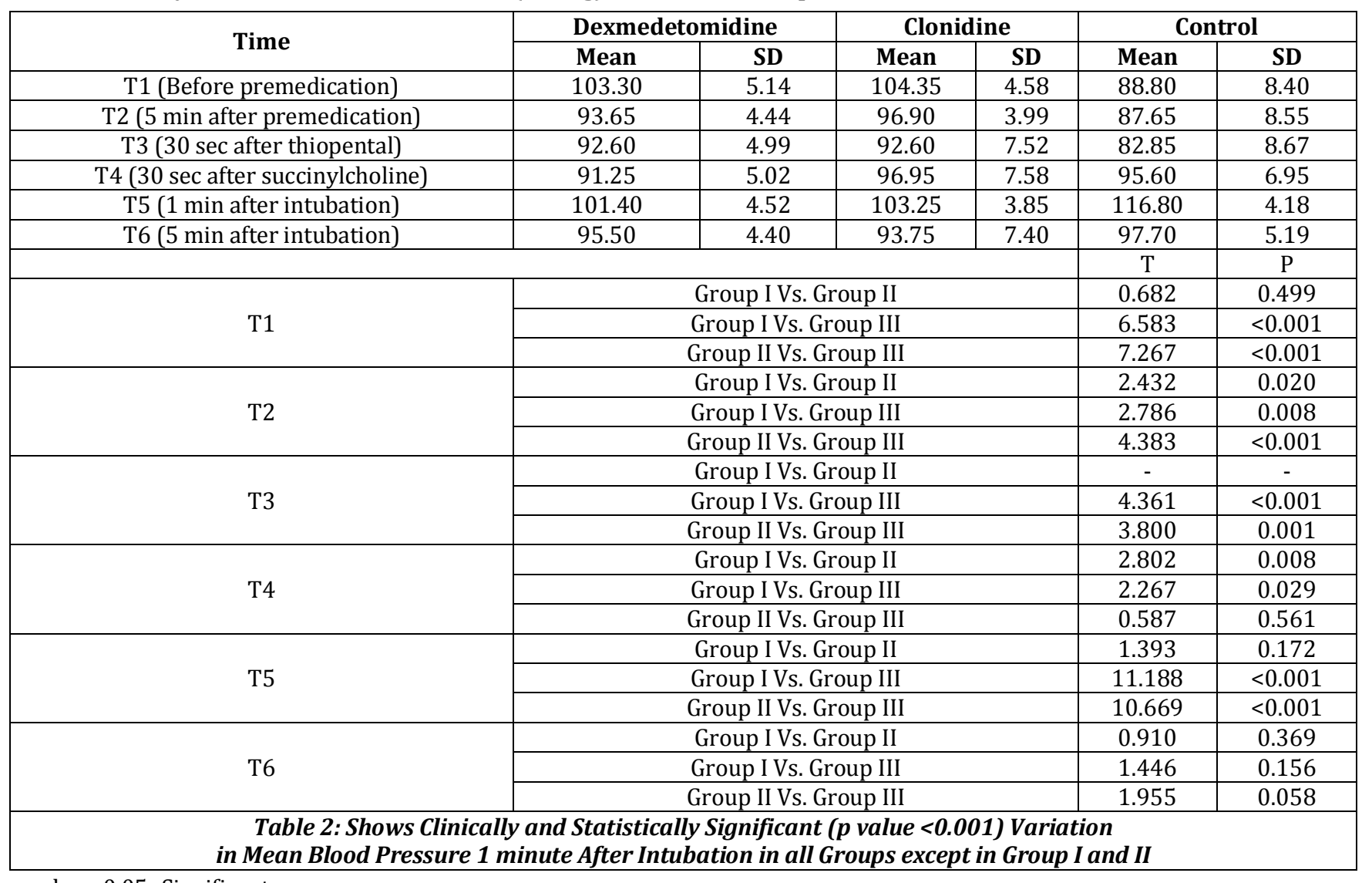

$\mathrm{p}$ value $<0.05$ - Significant

Statistical Analysis of IOP (mmHg) in all three Groups

\begin{tabular}{|c|c|c|c|c|c|c|}
\hline \multirow{2}{*}{ Time } & \multicolumn{2}{|c|}{ Dexmedetomidine } & \multicolumn{2}{|c|}{ Clonidine } & \multicolumn{2}{|c|}{ Control } \\
\hline & Mean & SD & Mean & SD & Mean & SD \\
\hline T1 (Before premedication) & 15.23 & 2.23 & 15.72 & 2.40 & 15.37 & 2.28 \\
\hline T2 (5 min after premedication) & 10.95 & 2.47 & 11.12 & 2.36 & 13.56 & 2.55 \\
\hline T3 (30 sec after thiopental) & 9.27 & 2.04 & 9.33 & 1.67 & 10.81 & 2.39 \\
\hline T4 (30 sec after succinylcholine) & 12.24 & 1.95 & 13.44 & 2.53 & 19.93 & 2.89 \\
\hline T5 (1 min after intubation) & 14.30 & 1.83 & 15.36 & 2.63 & 25.32 & 3.60 \\
\hline T6 (5 min after intubation) & 10.16 & 1.88 & 10.03 & 1.10 & 13.43 & 2.65 \\
\hline & & & & & $\mathrm{T}$ & $\mathrm{P}$ \\
\hline & & up IV & & & 0.661 & 0.513 \\
\hline $\mathrm{T} 1$ & & $\mathrm{p} \mathrm{IVs}$ & & & 0.189 & 0.851 \\
\hline & & $\mathrm{p}$ II V & III & & 0.473 & 0.639 \\
\hline & & up IV & & & 0.222 & 0.825 \\
\hline $\mathrm{T} 2$ & & Ip I Vs & & & 3.287 & 0.002 \\
\hline & & $\mathrm{p} \mathrm{II} \mathrm{V:}$ & & & 3.138 & 0.003 \\
\hline & & up I V: & & & 0.110 & 0.913 \\
\hline T3 & & ip I Vs & & & 2.199 & 0.034 \\
\hline & & $\mathrm{p} \mathrm{II} \mathrm{V.}$ & & & 2.268 & 0.029 \\
\hline & & up I V & & & 1.675 & 0.102 \\
\hline $\mathrm{T} 4$ & & $\mathrm{ip} \mathrm{IVs}$ & & & 9.846 & $<0.001$ \\
\hline & & $\mathrm{p}$ II V: & & & 7.556 & $<0.001$ \\
\hline & & up IV & & & 1.485 & 0.146 \\
\hline T5 & & $\mathrm{ip} \mathrm{IVs}$ & & & 12.201 & $<0.001$ \\
\hline & & $\mathrm{p} \mathrm{II} \mathrm{V.}$ & & & 9.982 & $<0.001$ \\
\hline & & up IV & & & 0.278 & 0.783 \\
\hline T6 & & ip I Vs & & & 4.507 & $<0.001$ \\
\hline & & $\mathrm{p}$ II V. & III & & 5.315 & $<0.001$ \\
\hline
\end{tabular}

$\mathrm{p}$ value $<0.05$-significant 
The study data analysed by using Analysis of Variance (ANOVA) and Student - t Test Chi square test SPSS software 10.0 .

\section{RESULT}

There were no significant differences between the two Groups with regard to age, weight and gender of the patients. Baseline HR. MAP AND IOP were also comparable. We observed the Pulse rate, Systolic blood pressure, Diastolic blood pressure, Mean arterial pressure and Intraocular pressure following laryngoscopy and intubation in all the 3 groups to various extent. The rise was maximum in Control Group, Pulse rate by 33.20 beats/minute, Systolic blood pressure by $35.8 \mathrm{mmHg}$, Diastolic blood pressure by $21.65 \mathrm{mmHg}$, Mean blood pressure by $28 \mathrm{mmHg}$ and intraocular pressure by $9.95 \mathrm{mmHg}$ above the baseline.

In Group I and II, Pulse rate, Systolic blood pressure, Diastolic blood pressure, Mean blood pressure and Intraocular pressure remained below the baseline. The rise was minimum in Group I. Pulse rate by 3.2 beats/minute, Systolic blood pressure by $3.85 \mathrm{mmHg}$, Diastolic blood pressure by 3.2 $\mathrm{mmHg}$, Mean arterial pressure by $1.9 \mathrm{mmHg}$ and Intraocular pressure by $0.93 \mathrm{mmHg}$ below the baseline. The rise was intermediate in Group II. Pulse rate by 2.65 beats/minute, Systolic blood pressure by $3.65 \mathrm{mmHg}$, Diastolic blood pressure by $0.55 \mathrm{mmHg}$, Mean blood pressure by $1.1 \mathrm{mmHg}$ and IOP by $0.36 \mathrm{mmHg}$ below the baseline.

Pulse rate, blood pressure (Systolic, Diastolic and Mean) and IOP differences were statistically significant $(\mathrm{p}$ value between 0.000 and 0.05 ) in Dexmedetomidine and Clonidine Group compared to Control Group 1 min and 5 minutes after intubation, but it was statistically insignificant ( $p$ value $>0.05$ ) between Dexmedetomidine and Clonidine Group. The common complications observed in this study were hypotension and bradycardia. One of the patients developed hypotension in Group I and Group II each, one patient developed bradycardia in Group II.

\section{DISCUSSION}

Patient with penetrating eye injury may present full stomach. Goal of anaesthesia in this scenario is to secure the airway by rapid sequence induction technique without increasing the IOP. Suxamethonium, the most commonly used muscle relaxant for rapid sequence airway management increases the IOP.

Clonidine is effective in preventing the rise in IOP in response to suxamethonium and endotracheal intubation. Dexmedetomidine has been found by various authors, blunt the rise in IOP associated with suxamethonium and intubation and also the haemodynamic response to laryngoscopy and endotracheal intubation. Dexmedetomidine infusion as an adjunct to local analgesia in eye surgery is effective in reducing the IOP significantly.

Dexmedetomidine administered intravenously in the dose of $0.6 \mu \mathrm{g} / \mathrm{kg}$ before induction as a premedicant significantly obtunded the rise in IOP following suxamethonium and intubation. Pal $\mathrm{CK}^{9}$ and Colleagues used dexmedetomidine in two doses $0.4 \mu \mathrm{g} / \mathrm{kg}$ and $0.6 \mu \mathrm{g} / \mathrm{kg}$ intravenously as premedicant and found that both doses lowered the IOP, but haemodynamic stability was better with $0.4 \mu \mathrm{g} / \mathrm{kg}$ dose.
In the year 2012, Rao ${ }^{10}$ gave the loading dose of $1 \mu \mathrm{g} / \mathrm{kg}$ of inj. Dexmedetomidine over 10 minutes before induction. There was a significant reduction in the Heart rate and Systolic blood pressure during intubation. In the year 2012, Panda ${ }^{11}$ used the infusion of Dexmedetomidine and Clonidine in the doses of $1 \mu \mathrm{g} / \mathrm{kg}$ in $100 \mathrm{~mL}$ normal saline 10 minutes before induction. Dexmedetomidine showed a significant decrease in Heart rate and Systolic blood pressure compared to Clonidine. Dexmedetomidine was well tolerated and no serious side effects or adverse reactions occurred. Similar results were observed in our study.

The effect of alpha- 2 agonists on the IOP may be due to its direct vasoconstrictor effect on the afferent blood vessels of the ciliary body leading to reduction of aqueous humour production. It may also facilitate the drainage of aqueous humour by reducing sympathetically mediated vasomotor tone of the ocular drainage system.

The main finding in our study was that dexmedetomidine and clonidine premedication in the dose of $1 \mu \mathrm{g} / \mathrm{kg}$ body weight given over 10 mins. before induction as a premedicant blunted the rise in IOP caused by suxamethonium, laryngoscopy and endotracheal intubation. Our study correlates with the studies done by G Weigert (2007)12, Mowafi (2008) ${ }^{7}$ and Pal CK (2011) ${ }^{8}$, as in all of their studies there is a reduction in IOP in dexmedetomidine and clonidine Groups at various time intervals.

Dexmedetomidine and clonidine premedication also produced significant fall in arterial pressure and HR. Even after intubation, MAP remained below baseline unlike the increase in MAP seen in control Group. The present study also observed significant attenuation of pressure response related to laryngoscopy and endotracheal intubation, which supports the statements made by previous workers.

\section{CONCLUSIONS}

From our study and observations, we can conclude that inj. Dexmedetomidine in a dose of $1 \mu \mathrm{g} / \mathrm{kg}$ given 10 minutes before induction is much more effective in controlling both the tachycardia, hypertension and IOP following laryngoscopy and intubation as compared to inj. Clonidine in a dose of $1 \mu \mathrm{g} / \mathrm{kg}$ given 10 minutes before induction. So in our study, Dexmedetomidine is a better drug than Clonidine to attenuate the haemodynamic changes and IOP due to laryngoscopy and intubation.

As we have studied in small group of patients (60), further studies are required to establish the use of Dexmedetomidine and Clonidine as routine premedication in all the patients undergoing surgery under general anaesthesia to attenuate the intraocular pressure and cardiovascular responses to laryngoscopy and intubation.

\section{REFERENCES}

1. Drenger B, Peer J. Attenuation of ocular and systemic responses to tracheal intubation by intravenous lignocaine. British Journal of Ophthalmology 1987;71(7):546-8.

2. Murthy VS, Hwang TF, Sandage BW. Esmolol and the adrenergic response to peri-operative stimuli. J Clin Pharmacol 1986;26:A27-A35. 
3. Murphy DF, Eustace $\mathrm{P}$, Unwin $\mathrm{A}$, et al. Intravenous lignocaine pre-treatment to prevent intraocular pressure rise following suxamethonium and tracheal intubation. Brit J Ophthalmology 1986;70(8):596-8.

4. Flacke JW, Bloor BC, Flacke WE, et al. Reduced narcotic requirement by clonidine with improved haemodynamic and adrenergic stability in patients undergoing coronary bypass surgery. Anaesthesiology 1987;67(1):11-9.

5. Ghignone $\mathrm{M}$, Noe $\mathrm{C}$, Calvillo $\mathrm{O}$, et al. Anaesthesia for ophthalmic surgery in the elderly: the effects of clonidine on intraocular pressure, perioperative haemodynamics, and anaesthetic requirement. Anaesthesiology 1988;68(5):707-16.

6. Aho M, Lehtinen AM, Erkola 0 , et al. The effect of intravenously administered dexmedetomidine on perioperative haemodynamics and isoflurane requirements in patients undergoing abdominal hysterectomy. Anaesthesiology 1991;74(6):997-1002.

7. Mowafi HA, Aldossary N, Ismail SA, et al. Effect of dexmedetomidine premedication on the intraocular pressure changes after succinylcholine and intubation. Brit J Anaesthesia 2008;100(4):485-9.
8. Shalini A, Srinivas VY, Gurudatt C. Dexmedetomidine premedication obtund the intraocular pressure rise after suxamethonium and endotracheal intubation. Journal of Evolution of Medical \& Dental Sciences 2014;3(27):74419.

9. Pal CK, Ray M, Sen A, et al. Changes in intraocular pressure following administration of suxamethonium and endotracheal intubation: influence of dexmedetomidine premedication. Indian J Anesthesia 2011;55(6):573-7.

10. Rao SH, Sudhakar B. Haemodynamic and anaesthetic advantages of dexmedetomidine. South Afr J Anaesth Analg 2012;18(6):326-31.

11. Panda BK, Singh P, Marne S. A comparison study of dexmedetomidine Vs clonidine for sympathoadrenal response, perioperative drug requirements and cost analysis. Asian Pacific J Tropical Diseases 2012;2(2):S81521.

12. Weigert G, Resch H, Luksch A, et al. Intravenous administration of clonidine reduces intraocular pressure and alters ocular blood flow. Brit J Ophthalmology 2007;91(10):1354-8. 